\title{
Evaluation of quality of life and self esteem in patients with malocclusion
}

\author{
Shanmuga Priya $S^{*}$ and Shyamla \\ Saveetha Dental College and Hospital, Chennai, Tamil Nadu, India
}

\begin{abstract}
Objective: the objective of the study is to develop a questionnaire to assess the psychosocial aspects which are considered important by orthodontic patients regarding their dento-facial deformity.
\end{abstract}

Background: Orthodontic treatment is an operation to reposition the upper, lower, or both jaws, in individuals who have a large discrepancy between the size of the jaws in relation to each other, or in whom the jaws are abnormally positioned in relation to the base of skull.

Reason: To evaluate the quality of life and self esteem in patients undergoing orthodontic treatment.

\section{Introduction}

Many people have crowded or crooked teeth. Orthodontic treatment will straighten the teeth or move them into a better position. This can improve their appearance and the way the teeth bite together, while also making them easier to clean.

When the teeth don't meet correctly, this can put strain on the muscles of the jaw, causing jaw and joint problems and sometimes headaches. Orthodontic treatment can help you to bite more evenly and reduce the strain.

The clinical focus on improving quality of life (QOL) and other psychological measures in cases of dental conditions that are not life threatening, and thus the psychological aspects of malocclusion and ortho-dontic treatment have become a popular topic in modern orthodontics [1,2].

Malocclusion represents only one dimension of the complex nature of oral health. However, malocclusion can affect self-satisfaction, and as a result, impair psychological and social functioning [3].

The term self-esteem is used to describe a person's overall sense of self-worth or personal value. Self-esteem can involve a variety of beliefs about the self, such as the appraisal of one's own appearance, beliefs, emotions, and behaviours. There has been a growing acceptance of the positive relationship between improvement in aesthetics and psychological profile [4].

\section{Materials and methods}

The first stage involved generating a list of items or questions, the content of which would reflect the impact of facial deformity on an individual's quality of life.

Evaluation of malocclusion is currently taken by 20 questions. A total of 30 patients were recruited for the study and the OQLQ was administered prior to any treatment and will also be administered after pre-surgical orthodontic treatment and at the end of treatment (Table 1) [8].

\section{Socioeconomic status}

A validated questionnaire in which demographic data and occupational and educational status of subjects is gathered as an indicator of socioeconomic status was used (Table 2) [5].

The Rosenberg Self-esteem scale [6] assessed the psychological influences of malocclusion and orthodontic treatment. This scale has proven reliability and validity for the general population and orthodontic patients [7]. The scale consists of 10 questions: 5 positive and 5 negative and uses a Likert scale, in which the responses for positive and negative questions are weighted differently, by a four-point scale, ranging from 'strongly agree; agree; disagree and strongly disagree. The scale ranges from 0 to 30, with scores of 15-25 indicating a normal self-esteem and scores of less than 15 indicating a low self-esteem.

\section{Results}

Results have been presented in the Tables 1,2 and 3 .

\section{Discussion}

The present study sample revealed that the majority of the participants were female than male. Females were more dissatisfied with the appearance of their dentition and perceived a need for braces more often than males.The overall self-esteem appeared high among the group, and therefore its impact on malocclusion was unlikely to

Correspondence to: Shanmuga Priya S, Saveetha Dental College and Hospital No.162, Poonamalle High Rd,, Velappanchavadi, Chennai, 600072, Tamil Nadu, India; E-mail: Spriyaa020@gmail.com

Received: May 02, 2015; Accepted: June 12, 2015; Published: June 15, 2015 
Table 1. Principal component analysis and internal consistency analysis [8].

\begin{tabular}{|c|c|c|c|c|c|}
\hline Sr. No. & Question & I-bothers a little & II-bothers a lot & $\begin{array}{c}\text { Lies between this } \\
\text { statement }\end{array}$ & Does not applicable \\
\hline 1 & I am self-conscious about the appearance of my teeth? & 10 & 15 & 3 & 2 \\
\hline 2 & I have problems biting? & 15 & 9 & 5 & 1 \\
\hline 3 & I have problems chewing? & 8 & 20 & 1 & 1 \\
\hline 4 & $\begin{array}{l}\text { There are some foods I avoid eating because the way my teeth meet } \\
\text { makes it difficult? }\end{array}$ & 25 & 3 & 2 & 0 \\
\hline 5 & I don't like eating in public places? & 11 & 14 & 3 & 2 \\
\hline 6 & I get pains in my face or jaw? & 7 & 6 & 12 & 5 \\
\hline 7 & I don't like seeing aside view of my face profile? & 17 & 3 & 5 & 5 \\
\hline 8 & I spend a lot of time studying my face in the mirror? & 13 & 13 & 2 & 2 \\
\hline 9 & I spend a lot of time studying my teeth in the mirror? & 3 & 17 & 5 & 5 \\
\hline 10 & I dislike having my photograph taken? & 10 & 10 & 7 & 3 \\
\hline 11 & I often stare at other people's teeth? & 7 & 8 & 10 & 5 \\
\hline 12 & I often stare at other people's faces? & 15 & 10 & 5 & 0 \\
\hline 13 & I am self conscious about my facial appearance? & 12 & 11 & 2 & 5 \\
\hline 14 & I try to cover my mouth when I meet people for the first time? & 9 & 9 & 7 & 6 \\
\hline 15 & I worry about meeting people for the first time? & 20 & 5 & 2 & 1 \\
\hline 16 & I worry that people will make hurtful comments about my appearance? & 18 & 7 & 5 & 0 \\
\hline 17 & I lack confidence when I am out socially? & 14 & 14 & 1 & 1 \\
\hline 18 & I do not like smiling when I meet people? & 16 & 11 & 2 & 1 \\
\hline 19 & I sometimes get depressed about my appearance? & 10 & 15 & 4 & 1 \\
\hline 20 & $\begin{array}{l}\text { Comments about my appearance really upset me, even when I know } \\
\text { people are only joking? }\end{array}$ & 19 & 8 & 2 & 1 \\
\hline
\end{tabular}

Table 2. Socio demographic characteristics of subjects.

\begin{tabular}{|c|c|c|}
\hline Gender & Male & 11 \\
& Female & 19 \\
\hline Age & Minimum & 16 \\
& Maximum & 35 \\
\hline \multirow{2}{*}{ Education } & Primary school & 8 \\
& Secondary school & 13 \\
\hline \multirow{2}{*}{ Occupation } & Under graduate & 5 \\
& Post graduate & 4 \\
\hline & student & 7 \\
& Full time employed & 8 \\
& Part time employed & 4 \\
& Self employed & 9 \\
\hline
\end{tabular}

be detected. The present finding has been supported by a number of studies confirming the presence of a dentofacial deformity and does not necessarily result in lower self-esteem [10-12].

The results from the current study found there was no statistically significant difference in self-esteem scores during orthodontic treatment. However, a significant difference was detected between the start and end of treatment. These results are in contrast to the findings from a longitudinal study on adult orthodontic patients in which orthodontic treatment was not found to affect self-esteem [13].

Self-esteem is influenced by many factors such as body image, facial image, stage of anxiety and depression, and social acceptance; therefore, the interaction with orthodontic treatment may be variable.
Table 3. Descriptive and comparative statistics of the overall self-esteem scores in the test group at baseline (T0), 1- (T1), 3- (T2), and 6-months (T3) and post-treatment (T4; n = 61) [9].

\begin{tabular}{|c|c|c|c|c|}
\hline Variable & Median & Minimum & Maximum & P value \\
\hline T0 & 23 & 8 & 30 & - \\
\hline T1 & 22 & 8 & 30 & 0.892 \\
\hline T2 & 21 & 8 & 30 & 0.727 \\
\hline T3 & 23 & 16 & 30 & 0.841 \\
\hline T4 & 26 & 18 & 30 & 0.002 \\
\hline
\end{tabular}

The findings of the present study suggest that orthodontic treatment might impart psychological benefits to adult patients.

\section{Conclusion}

Undergoing fixed orthodontic therapy appeared to have a more negative impact on the overall oral health related quality of life during the first 3 months of treatment, which then improved to pre-treatment scores. In contrast, a significant improvement was detected in self-esteem.

\section{References}

1. Shaw WC, Addy M, Ray C (1980) Dental and social effects of malocclusion and effectiveness of orthodontic treatment: a review. Community Dent Oral Epidemiol 8: 36-45. [Crossref]

2. de Oliveira CM, Sheiham A (2004) Orthodontic treatment and its impact on oral healthrelated quality of life in Brazilian adolescents. J Orthod 31: 20-27. [Crossref] 
3. de Oliveira CM, Sheiham A (2003) The relationship between normative orthodontic treatment need and oral health-related quality of life. Community Dent Oral Epidemiol 31: 426-436. [Crossref]

4. Maite clijmans, Jurgen Lemiere, Steffens Fieuws, Cury Willems (2015) Impact of self esteem and personality traits on association between orthodontic treatment and oral health related quality of life in adults. The European Journal of Orthodontics. 10.2093/ ejo/cju02.

5. McGrath C, Bedi R (1999) The value and use of 'quality of life' measures in the primary dental care setting. Prim Dent Care 6: 53-57. [Crossref]

6. Rosenberg M (1965) Society and the Adolescent Self-Image . Wesleyan University Press, Middletown, CT.

7. Shaw WC, Richmond S, Kenealy PM, Kingdon A, Worthington H (2007) A 20-year cohort study of health gain from orthodontic treatment: psychological outcome. Am J Orthod Dentofacial Orthop 132: 146-157. [Crossref]

8. Cunningham SJ, Garratt AM, Hunt NP (2000) Development of a condition-specific quality of life measure for patients with dentofacial deformity: I. Reliability of the instrument. Community Dent Oral Epidemiol 28: 195-201. [Crossref]

9. Johal A, Alyaqoobi I, Patel R, Cox S1 (2015) The impact of orthodontic treatment on quality of life and self-esteem in adult patients. Eur J Orthod 37: 233-237. [Crossref]

10. Hassan AH, Amin Hel-S (2010) Association of orthodontic treatment needs and oral health-related quality of life in young adults. Am J Orthod Dentofacial Orthop 137: 42-47. [Crossref]

11. O’Regan JK, Dewey ME, Slade PD, Lovius BB (1991) Self-esteem and aesthetics. $B r$ J Orthod 18: 111-118. [Crossref]

12. Varela M, García-Camba JE (1995) Impact of orthodontics on the psychologic profile of adult patients: a prospective study. Am J Orthod Dentofacial Orthop 108: 142-148. [Crossref]

13. Shaw WC, Richmond S, Kenealy PM, Kingdon A, Worthington H (2007) A 20-year cohort study of health gain from orthodontic treatment: psychological outcome. Am J Orthod Dentofacial Orthop 132: 146-157. [Crossref]

Copyright: (C2015 Priya SS. This is an open-access article distributed under the terms of the Creative Commons Attribution License, which permits unrestricted use, distribution, and reproduction in any medium, provided the original author and source are credited. 